\title{
Surgically assisted techniques to accelerate tooth movements, a call to cooperation.
}

\begin{abstract}
Ricardo Cartes-Velásquez ${ }^{1}$, Jorge Jofré ${ }^{2}$
1. Odontología, Fundación Kimntrum, Concepción, Chile.

2. Center for Advanced Prosthodontics \& Implant Dentistry, Universidad de Concepción, Concepción, Chile.

* Corresponding author: Ricardo CartesVelásquez | Dirección: Beltrán Mathieu 7. Concepción | Télefono: +569 77575655 | Email: cartesvelasquez@gmail.com

Work received on 05/11/2020.

Approved for publication on 13/12/2020

\section{ORCID}

Ricardo Cartes-Velásquez

orcid.org/0000-0001-5831-7324

\section{Dear Editor,}

Treatment duration is a major issue in orthodontics, which has motivated the proposal and evaluation of several methods in order to shorten this period ${ }^{(1)}$. This situation is especially relevant in countries like Chile, where the prevalence of dentofacial abnormalities and their impacts are higher (2).

Surgically assisted techniques to accelerate tooth movements have shown predictable results ${ }^{(1)}$, causing reversible bone injury by providing a period of less resistance to tooth movement, known as the regional acceleratory phenomenon $\operatorname{RAP}^{(3)}$. However, the main disadvantage of these kinds of procedures is their invasiveness, producing discomfort and dizziness in patients. In our center, we have been pioneers in evaluating less invasive techniques, which showed to be as effective as others in reducing treatment duration, but with minimal discomfort for the patients ${ }^{(4)}$. The evolution of these flapless procedures shows us an even simpler and promising approach called piezopuncture, which avoids the need for surgical guides and the risk of residual scars.

This new, minimally invasive therapeutic procedure takes only a few minutes to perform and uses a sharp ultrasonic piezosurgical tip to create cortical punctures through the gingiva, on the mesial and distal sides of each tooth. Patients have received this procedure very well, and have not manifested postoperative discomfort or required analgesics or antiinflammatories. It is important to consider that the gingiva should only be punctured for a second or two, since staying with any ultrasound insert for a longer time in areas of thick gingival phenotypes does not allow cooling of the tip, which can cause exaggerated damage.

Piezopuncture can accelerate the rate of tooth movement by evoking RAP without causing collateral damage ${ }^{(5)}$. We have evidence showing the clinical advantages of this technique, but larger and longer clinical studies ${ }^{(4)}$ are required to confirm these findings. The possibility of having a simple and safe tool to reduce the duration of orthodontic treatments would be especially impactful in our public dental services, where there is an extensive waiting list of orthodontic patients. This situation is probably similar in many orthodontic clinics in Chilean dental schools as well as across the globe.

Thus, based on the current evidence on piezopuncture and our epidemiological needs, cooperative research on this matter is crucial. Moreover, in addition to a high level of evidence, we also require evidence that is relevant to our clinical and material conditions/situations.
\end{abstract}

\section{References}

1. Verna C. Regional acceleratory phenomenon. Front Oral Biol. 2016;18:28-35. 2. Cartes-Velásquez R, Araya $E$, Valdés $C$. Maloclusiones y su impacto psicosocial en estudiantes de un liceo intercultural. Int J Odontostomat. 2010;4(1):65-70. 3. Fisher MA, Wenger RM, Hans MG. Pretreatment characteristics associated with orthodontic treatment duration. Am J Orthod Dentofacial Orthop. 2010;137:178-86.
4. Jofre J, Montenegro J, Arroyo R. Rapid orthodontics with flapless piezoelectric corticotomies: first clinical experiences. Int J Odontostomat. 2013;7:79-85.

5. Kim YS, Kim SJ, Yoon HJ, Lee PJ, Moon W, Park Y-G. Effect of piezopuncture on tooth movement and bone remodeling in dogs. Am J Orthod Dentofacial Orthop. 2013;144:23-31. 